\title{
Offshore AC Grid Management for an AC Integrated VSC- HVDC Scheme with Large WPPs
}

DOI:

10.1109/PESGM.2016.7741225

Link to publication record in Manchester Research Explorer

\section{Citation for published version (APA):}

Shah, R., Barnes, M., \& Preece, R. (2016). Offshore AC Grid Management for an AC Integrated VSC-HVDC Scheme with Large WPPs. In 2016 IEEE PES GM Proceedings IEEE.

https://doi.org/10.1109/PESGM.2016.7741225

\section{Published in:}

2016 IEEE PES GM Proceedings

\section{Citing this paper}

Please note that where the full-text provided on Manchester Research Explorer is the Author Accepted Manuscript or Proof version this may differ from the final Published version. If citing, it is advised that you check and use the publisher's definitive version.

\section{General rights}

Copyright and moral rights for the publications made accessible in the Research Explorer are retained by the authors and/or other copyright owners and it is a condition of accessing publications that users recognise and abide by the legal requirements associated with these rights.

\section{Takedown policy}

If you believe that this document breaches copyright please refer to the University of Manchester's Takedown Procedures [http://man.ac.uk/04Y6Bo] or contact uml.scholarlycommunications@manchester.ac.uk providing relevant details, so we can investigate your claim.

\section{OPEN ACCESS}




\title{
Offshore AC Grid Management for an AC Integrated VSC-HVDC Scheme with Large WPPs
}

\author{
Rakibuzzaman Shah, Member, IEEE, Mike Barnes, Senior Member, IEEE, and Robin Preece, Member, IEEE \\ School of Electrical and Electronic Engineering \\ The University of Manchester \\ Manchester, M13 9PL, United Kingdom \\ E-mail: rakibuzzaman.shah@manchester.ac.uk; mike.barnes@manchester.ac.uk; robin.preece@manchester.ac.uk
}

\begin{abstract}
Point-to-point VSC-HVDC Wind power plant (WPP) links connected offshore by AC cables can be called an AC integrated VSC-HVDC scheme or virtual multi-terminal DC (MTDC) grid. Since, the AC integrated VSC-HVDC scheme forms an offshore AC grid, parallel operation of offshore VSCHVDC converters is required. This paper compares three offshore converter control topologies: (i) feedforward control of AC voltage and frequency, (ii) feedback control of AC voltage, and (iii) feedback control of AC voltage and frequency with an inner current loop. The performance of power and current based droops has been assessed for the parallel offshore converters. Simulations carried out in DIgSILENT Power Factory are presented to illustrate the effect of these offshore converter control strategies on the dynamics of the AC system following the offshore grid disturbances.
\end{abstract}

Index Terms-AC integrated scheme, droop control, offshore disturbances, offshore AC grid, wind power plants.

\section{INTRODUCTION}

It is anticipated that a large number of future wind power plants (WPPs) seeking transmission connection will be located offshore [1]. Many of the proposed offshore WPP projects are located a significant distance from shore (greater than 100 $\mathrm{km}$ ), therefore, HVDC is a strong option for connecting those WPPs. The characteristics of VSC-HVDC (i.e., no voltage polarity reversal, ability to connect remote grid, a small footprint) make it the natural choice for offshore WPP applications [2].

To date, most worldwide VSC-HVDC installations are point-to-point. However, the growing desire to interconnect the various regions within the Europe and North Sea countries may lead to multi-terminal DC (MTDC) grids [2]. Moreover, if built, the often proposed MTDC 'Supergrid' for North Sea countries will be pieced together gradually with the most likely first step being based on integrating offshore WPPs by AC cables to form an offshore AC grid [3]. Such a system can exist without the need for DC circuit breakers or DC protection schemes. Furthermore, connecting multiple preexisting VSC-HVDC systems with different DC voltages would not be a limiting factor for this configuration as the interconnection is made on the AC side. A similar idea, termed 'radial plus' was proposed by the UK Transmission System Operator, National Grid, to connect HVDC-links in offshore by AC cables [4]. Subsequently, it is anticipated that a large number of Round 3 offshore wind resources in the UK will be interconnected by using a 'radial plus' scheme [4].

The application of VSC-HVDC under an AC integrated topology with offshore AC grids poses a number of technical challenges including the control strategy and control coordination among the VSC-HVDCs. A number of state-ofthe-art control topologies for the offshore VSC-HVDC converter are proposed in [2],[3],[5]-[7] with the majority based on a 'direct voltage' control method of the VSC-HVDC. A droop control method is not considered except in [3], as most of these control topologies are proposed for point-topoint VSC-HVDC configurations. In [3], only the powerfrequency droop method is considered and the performance of the controller under offshore fault conditions is not presented. For the better management of AC integrated VSC-HVDC, a full understanding of different offshore VSC-HVDC control topologies and their impact on the system performance is required. Therefore, this paper compares three state-of-the-art offshore VSC-HVDC control topologies with two different droop control methods: (1) conventional voltage-reactive power $(V-Q)$ with frequency-active power $(f-P)$, and (2) voltage-reactive current $(V-I q)$ with frequency-active current $\left(f-I_{p}\right)$. Offshore grid disturbances are applied to assess the impact of these control topologies on the dynamic performance of a complex power system.

\section{OFFSHORE VSC-HVDC CONTROL}

A number of different control topologies have been proposed in the literature for an offshore VSC-HVDC converter to regulate the voltage and frequency at the point of common coupling (PCC) to the desired reference. This controller design means that the offshore converter acts as an infinite bus for connected WPPs to absorb all produced power [2],[3],[5]-[7]. Figure 1 shows the three state-of-the-art control topologies studied in this paper. 


\section{A. Offshore Converter Control Topologies}

Figure 1(a) shows a simple feedforward or 'direct voltage' grid forming converter controller for offshore VSC-HVDC converter, referred to as feedforward control. This control does not inherently include an inner current control loop. Hence, the direct control method has been used to manipulate directly the voltage and frequency. Supplementary control can then be added to adjust the frequency and voltage magnitude as a function of active and reactive power.

Figure 1(b) shows the offshore converter control topology where an AC voltage feedback loop has been used, which is referred to as voltage feedback control. For this control, AC voltage is regulated by adjusting the q-axis reference current signal using a PI-based voltage controller [6], [7]. A constant frequency signal is applied into the converter to control the voltage on the reference frequency.

Figure 1(c) shows the feedback type AC voltage and frequency control topology referred to here as feedback control. From Figure 1(c), it can be seen that this control topology utilizes inner current control loops. The inner current loops are used such that the current limits for d-and qaxis can be enforced. The AC voltage is controlled by adjusting the d-axis reference current, and the frequency is controlled by manipulating the q-axis reference current as in [2].

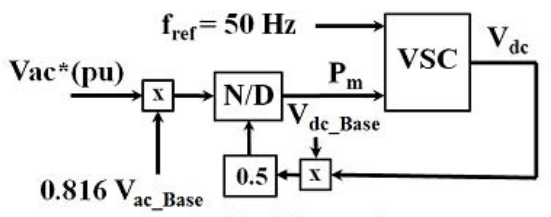

(a) Feedforward

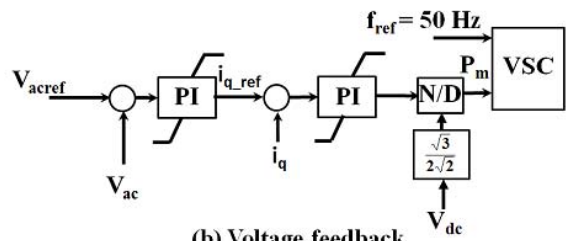

(b) Voltage feedback $\mathbf{V}_{\mathrm{dc}}$

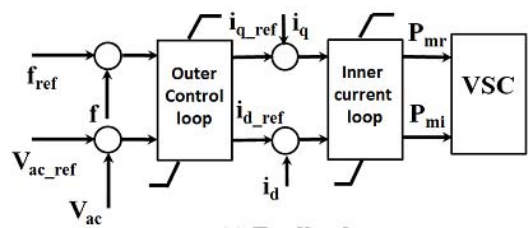

(c) Feedback

Figure 1. Offshore grid forming converter control topologies.

\section{B. Droop Control}

In this study, $\mathrm{AC}$ voltage and frequency droop characteristics are used in the offshore VSC-HVDC converters to adjust the $\mathrm{AC}$ voltage and frequency references. Figure 2 (a) shows the VSC-HVDC AC voltage and frequency droop characteristics with respect to reactive and active power. From this figure, it can be seen that the AC voltage characteristic of a VSC-HVDC is similar to that of a STATCOM. The reactive power injection and absorption of a VSC-HVDC converter is achieved based on (1).

$$
V_{A C}=V_{A C_{-} r e f}+k_{Q s l o p e}\left(Q_{\text {ref }}-Q\right)
$$

Based on the power dependent frequency droop, the coordination among the VSCs can be achieved based on (2).

$$
f=f_{\text {ref }}+k_{\text {fslope }}\left(P_{\text {ref }}-P\right)
$$

Figure 2 (b) shows the VSC-HVDC AC voltage and frequency droop characteristics in terms of reactive and active current as suggested in [8]. This droop control method can limit the current during the short-circuit condition as proposed in [8]. The AC voltage and frequency control for a VSCHVDC converter can be achieved based on (3) and (4).

$$
\begin{aligned}
& V_{A C}=V_{A C_{-} \text {ref }}+k_{\text {Qslope }}\left(I_{\text {qref }}-I_{q}\right) \\
& f=f_{\text {ref }}+k_{\text {fslope }}\left(I_{\text {pref }}-I_{p}\right)
\end{aligned}
$$
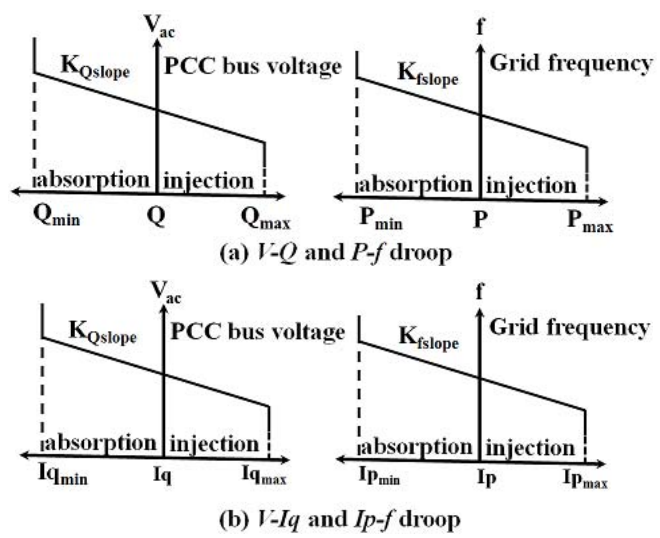

Figure 2. VSC-HVDC droop characteristics.

\section{AC-DC TEST SYSTEM}

The schematic illustration of the AC-DC test system is shown in Figure 3. The model was developed in DIgSILENT Power Factory 15.1. From the figure, it can be seen that a twoarea system has been used as an onshore AC network. Standard parameters of the two-area system are used as in [9]. However, the system fundamental frequency has been changed to $50 \mathrm{~Hz}$. The loads of the system at bus 7 and 9 are increased by $750 \mathrm{MW}$ to necessitate the transmission of offshore wind power to the onshore AC system. DC choppers are connected at the grid side converters for onshore fault ridethrough and are modelled as voltage controlled current sources as in [10]. The grid side converters are considered to be operated in DC voltage-reactive power control mode. The eight aggregated full converter wind turbines with total capacity of $1500 \mathrm{MW}$ are connected to the onshore network by two parallel VSC-HVDC links. Each converter is rated at $800 \mathrm{MVA}, \pm 320 \mathrm{kV}$ in a symmetrical monopole scheme. The DC link and wind generator parameters are given in the Appendix. A $10 \mathrm{~km}$ cable integrates the two VSC-HVDC links offshore to form an AC integrated VSC-HVDC scheme. As the schematic diagram shows, a 33/0.4 kV two winding step up transformer connects each wind generator to the medium voltage (MV) bus. In the model, parallel transformers are aggregated for each MV collector. Four 220/33/33 kV transformers are used to connect the medium and high voltage buses in the offshore grid. A MV $(33 \mathrm{kV})$ cable connector 
(10 km length) is used to interconnect the MV bus and the $33 \mathrm{kV}$ side terminals of the three winding transformers. Four $325 / 220 \mathrm{kV}$ transformers are used to connect the high voltage buses to the PCC. Tables I and II present the offshore grid and transformer parameters, respectively.

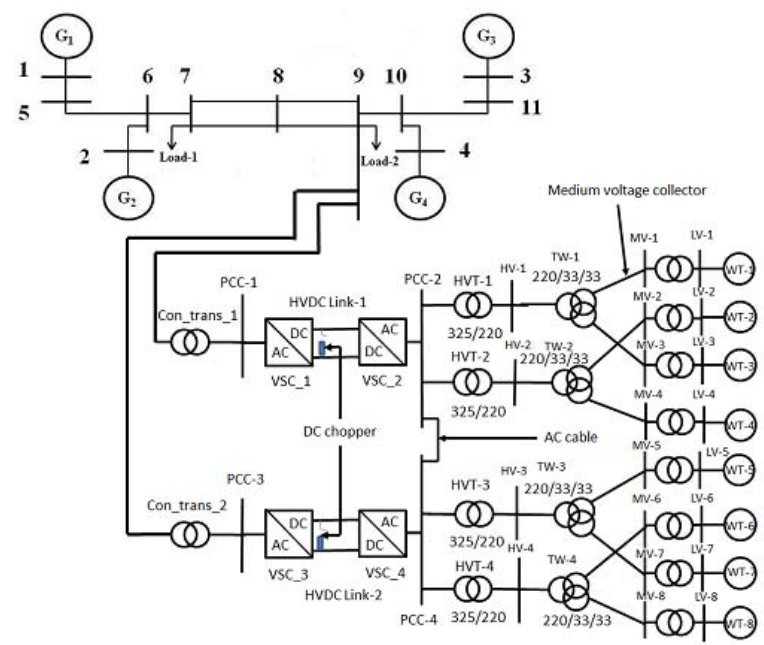

Figure 3. Schematic diagram of AC-DC test system.

TABLE I

OFFSHORE GRID PARAMETERS

\begin{tabular}{|c|c|c|c|c|c||}
\hline Elements & $\begin{array}{c}\text { Voltage } \\
(\mathbf{k V})\end{array}$ & $\begin{array}{c}\text { Current } \\
(\mathbf{k A})\end{array}$ & $\begin{array}{c}\mathbf{R} \\
(\mathbf{o h m} / \mathbf{k m})\end{array}$ & $\begin{array}{c}\mathbf{L} \\
(\mathbf{m H} / \mathbf{k m})\end{array}$ & $\begin{array}{c}\mathbf{C} \\
(\boldsymbol{\mu} \mathbf{F} / \mathbf{k m})\end{array}$ \\
\hline $\begin{array}{c}\text { MV } \\
\text { collector }\end{array}$ & 33 & 0.41 & 0.0754 & 0.33 & 0.00073 \\
\hline AC cable & 325 & 3.2 & 0.0529 & 1.68 & 0.0105 \\
\hline
\end{tabular}

TABLE II

OFFSHORE GRID TRANSFORMER PARAMETERS

\begin{tabular}{||l|c|c|c|c||}
\hline Transformer & $\begin{array}{c}\text { Rated power } \\
\text { (MVA) - (no. } \\
\text { of } \\
\text { transformer) }\end{array}$ & $\begin{array}{c}\text { Copper } \\
\text { loss (kW) }\end{array}$ & $\begin{array}{c}\text { Short- } \\
\text { circuit } \\
\text { voltage } \\
(\boldsymbol{\%})\end{array}$ & Vector group \\
\hline Low-voltage & $5.556-(300)$ & 20 & 6 & YN-D \\
\hline Medium & $500 / 250 / 250$ & HV-30 & HV-13 & YN-D-D \\
voltage & $-(4)$ & MV-20 & MV-10 & \\
\hline High voltage & $1000-(4)$ & 4,988 & 15 & YN-YN \\
\hline
\end{tabular}

"HV-High voltage; MV-Medium voltage; LV-Low voltage

\section{Simulation StUdies}

The following offshore disturbances have been applied to the system to compare the effect of different offshore grid forming converter control topologies on the system performance:

a) A sudden outage of the offshore wind generators.

b) Offshore AC fault (3-phase, $100 \mathrm{~ms}$ fault duration).

\section{A. Sudden Outage of Offshore Wind Generators}

For this study, a sudden outage of the offshore wind generator of $315 \mathrm{MW}$ equivalent capacities is considered to investigate the performance of the featured control topologies. The offshore converter active power responses following the outage of $315 \mathrm{MW}$ of offshore wind power are shown in
Figure 4. From the figure, it can be seen that the power flow takes $0.06 \mathrm{~s}$ to reach the new power flow point for all the featured control topologies. From the figure, it is also worth noting that voltage feedback and feedback control with power based droop show lower excursion of active power following the outage of WPPs. Figure 5 shows the PCC frequency responses following the outage of offshore WPPs.

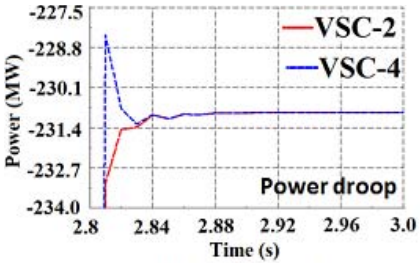

(a) Feedforward

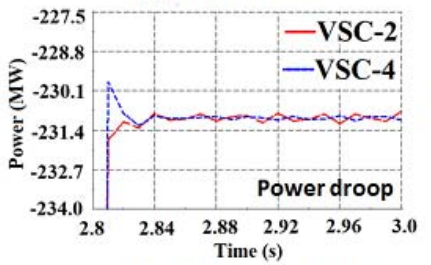

(b) Voltage feedback

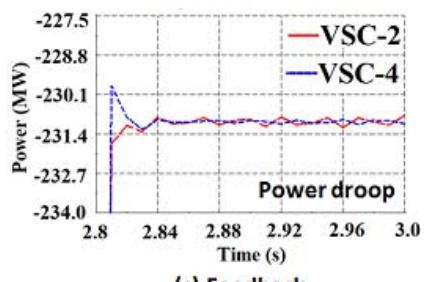

(c) Feedback

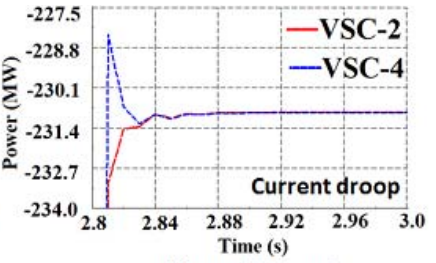

(d) Feedforward

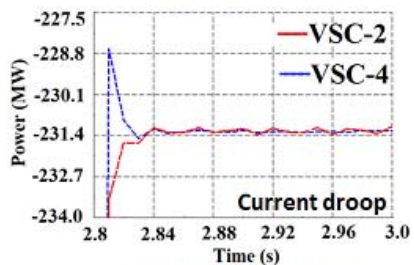

(e) Voltage feedback

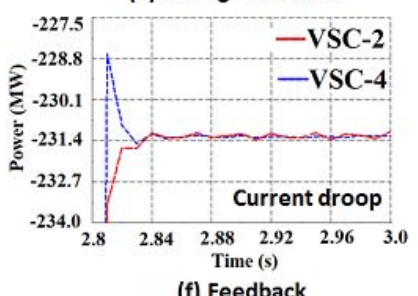

(f) Feedback
Figure 4. Offshore converter active power following the outage of WPPs.

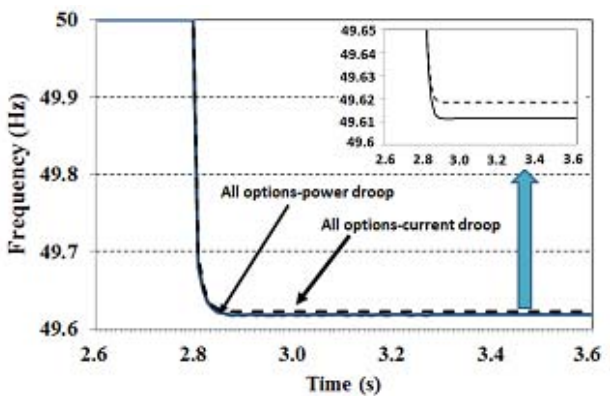

Figure 5. PCC frequency responses following the outage of WPPs.

From the figure, it can be seen that the PCC frequency takes $0.06 \mathrm{~s}$ to settle in a new frequency point. As the power being absorbed by the offshore VSC-HVDC converters is reduced, the frequency reduces as per the frequency droop characteristics presented in Figure 2 (a)-(b). This demonstrates that all droop control have the desired effect.

\section{B. Offshore AC Fault}

This case study investigates the AC integrated VSCHVDC scheme effect on system dynamic behavior when an offshore AC system fault occurs. A self-clearing 3-phase fault has been applied to bus HV-2 (see. Figure 3) at the offshore grid for $100 \mathrm{~ms}$, and the responses of the system's AC and DC side quantities are recorded. Figure 6 shows the offshore converter active power responses for the featured offshore 
converter control topologies presented in Section II for both power and current based droop control. From Figure 6, it can be seen that for the feedforward option, following a 3-phase fault at bus $\mathrm{HV}-2$, both the offshore converters experience a larger active power reduction compared to the other two options. Since, the feedforward option does not impose control limits except the limits of the droop control, the offshore converters are injecting more reactive power during the fault, resulting in less capacity for active power. On the other hand, the voltage feedback and feedback options have control limits on both outer and inner control loops preventing the excessive injection of reactive power during the fault. Hence, a smaller reduction of active power can be observed. Furthermore, an active power deviation between the offshore converters can be seen during the offshore fault when the current based droop control is used. Since, the current based droop control is more sensitive to the network impedance (compared to the power based droop control); this results in a deviation of active power between the converters when the system impedance changes during the fault.

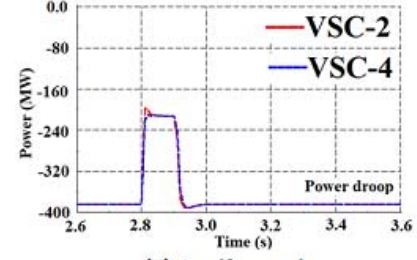

(a) Feedforward

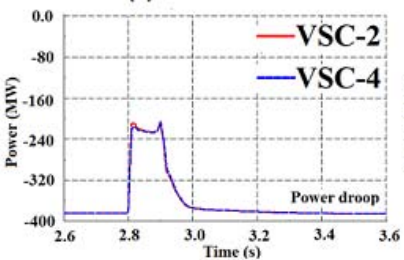

(b) Voltage feedback

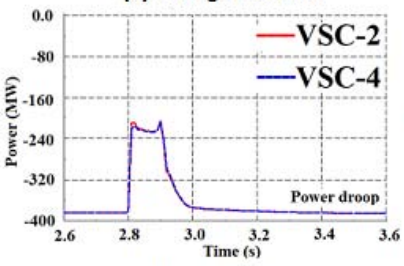

(c) Feedback

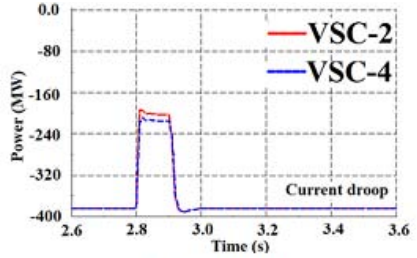

(d) Feedforward

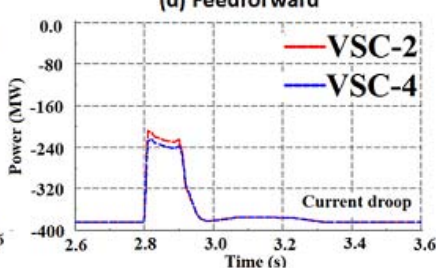

(e) Voltage feedback

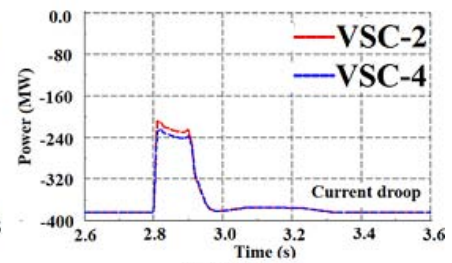

(f) Feedback
Figure 6. Offshore converter active power following a three-phase fault at offshore grid.

To highlight the importance of the impedance for current based droop, the offshore interconnector is reduced in length from $10 \mathrm{~km}$ to $5 \mathrm{~km}$. Figure 7 shows the converter active power following the 3-phase fault in the offshore grid for the new offshore interconnector length of $5 \mathrm{~km}$. From the figure, it can be seen that both power and current based droop control topologies result in similar performance when the distance (i.e., impedance) between two offshore converters is reduced. Furthermore, Table III shows the relative reactive power sharing error between the offshore converters during the fault with respect to VSC-2 reactive power (see. Figure 3). The relative reactive power sharing error is evaluated based on (5)

$$
\Delta Q_{e r r}=\frac{Q_{V S C 2}-Q_{V S C 4}}{Q_{V S C 2}}
$$

From the table it can be seen that the relative reactive power sharing error is high for current based droop in all featured control topologies. Moreover, it is worth noting that the relative reactive power sharing error increases with the increment of the $\mathrm{AC}$ interconnector length for the both droop methods.

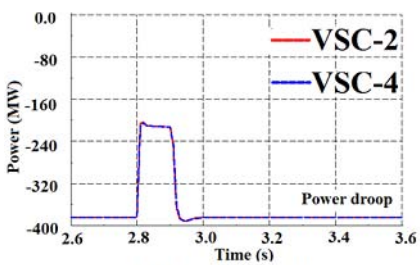

(a) Feedforward

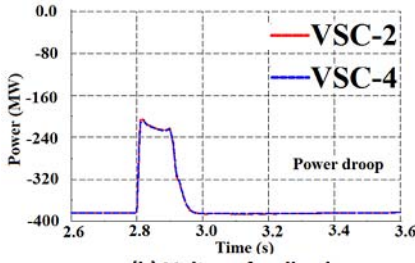

(b) Voltage feedback

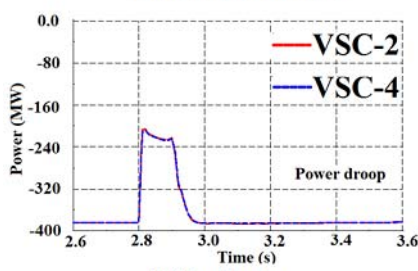

(c) Feedback

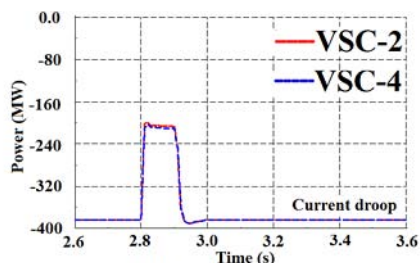

(d) Feedforward

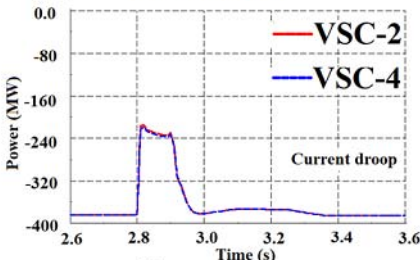

(e) Voltage feedback

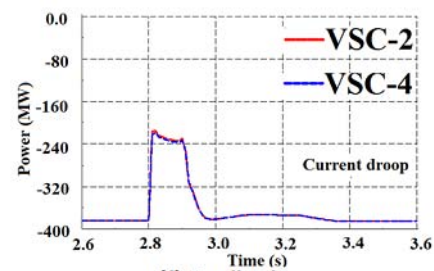

(f) Feedback

Figure 7. Offshore converter active power following a three-phase fault at offshore grid (reduced interconnection cable length).

TABLE III

REACTIVE POWER SHARING ERROR

\begin{tabular}{||c|c|c|c|c||}
\hline \multirow{2}{*}{$\begin{array}{c}\text { Droop } \\
\text { type }\end{array}$} & $\begin{array}{c}\text { Length of } \\
\text { offshore AC } \\
\text { interconnector }\end{array}$ & Feedforward & $\begin{array}{c}\text { Voltage } \\
\text { feedback }\end{array}$ & Feedback \\
\hline \multirow{3}{*}{ Power } & $5 \mathrm{~km}$ & 0.015 & 0.004 & 0.004 \\
\cline { 2 - 5 } & $10 \mathrm{~km}$ & 0.035 & 0.009 & 0.009 \\
\cline { 2 - 5 } & $20 \mathrm{~km}$ & 0.06 & 0.014 & 0.013 \\
\hline \multirow{3}{*}{ Current } & $5 \mathrm{~km}$ & 0.055 & 0.008 & 0.008 \\
\cline { 2 - 5 } & $10 \mathrm{~km}$ & 0.100 & 0.025 & 0.022 \\
\cline { 2 - 5 } & $20 \mathrm{~km}$ & 0.17 & 0.031 & 0.030 \\
\hline
\end{tabular}

Figure 8 shows the offshore high voltage bus (HV-1) voltage responses following the fault at $\mathrm{HV}-2$. From the figure, it can be observed that feedforward option displays faster voltage recovery following a 3-phase fault at HV-2 for both power and current based droop. From the figure, it is also reveals that the voltage recovery time depends on the current limits imposed on the voltage control loop in voltage feedback and feedback control options. A lower current limit leads to the slower bus voltage recovery in the offshore grid.

\section{Large-disturbance Rotor Angle Stability Assessment}

The large-disturbance rotor angle stability of the system is assessed by evaluating the transient stability margin of the system. It has been evaluated by using transient stability index (TSI ) as given in (6) [11] 

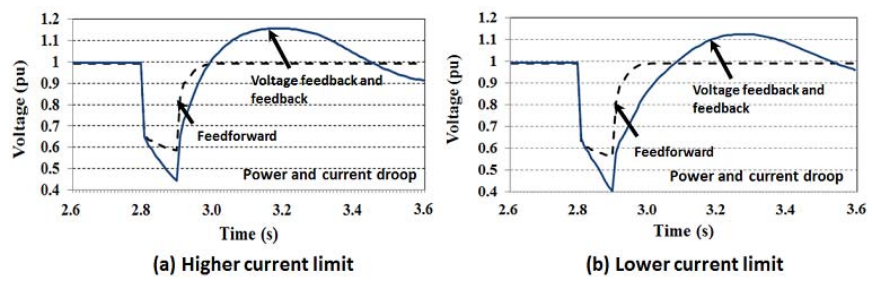

Figure 8. Offshore bus voltage responses following a three-phase fault at offshore grid.

$$
T S I=\frac{360^{0}-\delta_{M A X}}{360^{0}+\delta_{M A X}}
$$

where $\delta_{M A X}=$ maximum rotor angle separation between two synchronous generators at any instant time. In this study, $\delta_{M A X}$ of any $\mathrm{i}^{\text {th }}$ generator is calculated with respect to the reference machine rotor angle $\left(\delta_{\text {ref }}\right)$ which in (7) [11]

$$
\delta_{\text {MAX }}=\delta_{i}-\delta_{\text {ref }}
$$

If the TSI is less than zero, the system is large-disturbance rotor angle unstable. The power system is considered as stable for a TSI greater than zero. A higher TSI means a better transient stability margin for the system. Figure 9 shows the TSI of the system for the featured offshore converter control topologies. From the figure, it can be observed that TSI of the system does not change very significantly with different control options. However, it is worth noting that system shows a higher TSI for all control options with power based droop as compared to the current based droop. From Figure 9, it can also be seen that a system with the voltage feedback and feedback option shows higher TSI than the system with the feedforward control option.

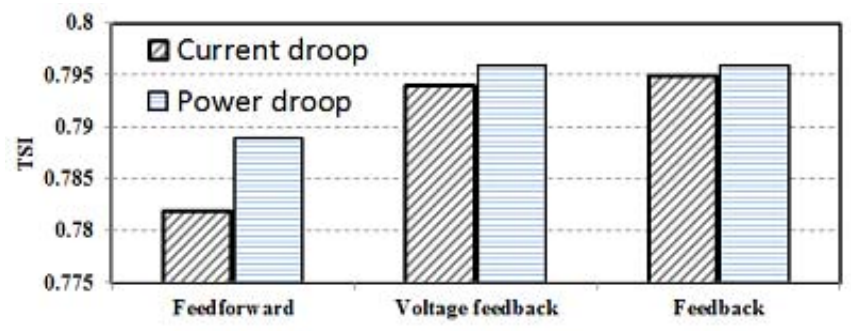

Figure 9. Transient stability index (TSI).

\section{CONCLUSIONS}

An integrated AC-DC system model is developed here for large-WPP integration consisting of an AC integrated VSCHVDC scheme. Based on the integrated AC-DC system model, the performance of different grid forming converter control topologies has been analysed for power and current based droop control methods. From this analysis, it has been shown that the simplest feedforward type grid forming converter shows the faster response following the offshore grid fault. However, this control option requires a very high value of $V-Q$ droop gain to limit the injection of reactive power during the offshore grid fault. From the analysis, it is also found that the power based droop control method displays better reactive power sharing than the current based droop method for all grid forming converter control topologies during the offshore AC grid fault. Although, a little performance difference was observed between voltage feedback and feedback control topology, it must be noted that the performance of feedback control topology may greatly be influenced by the stability of the phase locked loop. Little difference was observed with respect to the rotor angle stability of the system when using the different control topologies. However, it was found that controllers with a power based droop display marginally better rotor angle stability as compared to current based droop.

\section{APPENDIX}

DC line parameters: $R=0.0113 \mathrm{ohm} / \mathrm{km}, L=0.48 \mathrm{mH} / \mathrm{km}$, $C=0.33 \mu \mathrm{F} / \mathrm{km}$. DC link $=0.45 \mu \mathrm{F}$. Series reactor: $R=1.25$ $\mathrm{ohm} ; L=39.46 \mathrm{mH}$. Connection Transformer Con_trans_1 and $\_2: 325 / 230 \mathrm{kV}$ with $15 \%$ short-circuit voltage.

Wind generator parameters: Apparent power $=5.556 \mathrm{MVA}$, Number of wind generator $=300$, Power factor $=0.9, k_{d q}=1$

$\mathrm{pu}, T_{d q}=0.002 \mathrm{~s}, k_{p P Q}=0.1 \mathrm{pu}, k_{i P Q}=31.9 \mathrm{pu}$.

\section{ACKNOWLEDGEMENT}

This work is supported by Engineering and Physical Sciences Research Council (EPSRC) funded project on Multi-Terminal VSC-HVDC Networks: Grid Control (EP/L021463/1).

\section{REFERENCES}

[1] "The European offshore wind industry-key trends and statistics 1st half 2015," The European Wind Energy Association [Online]. Available: http://www.ewea.org [Accessed 27 Oct. 2015].

[2] N. R. Chaudhuri, B. Chaudhuri, R. Majumder, and A. Yazdani, Multiterminal Direct Current Grid: Modelling, Analysis and Control. NJ, USA: John Willey \& Sons, inc., 2014.

[3] X. Hu, J. Liang, D. J. Rogers, and Y. Li, "Power flow and power reduction control using variable frequency of offshore AC grids," IEEE Trans. Power Systems, vol. 28, no. 4, pp. 3897-3905, Nov. 2013.

[4] "National grid electricity ten years statement," National Grid Electricity Transmission plc: [Online]. Available: http:// www.nationalgrid.com [Accessed 28 Sept. 2015].

[5] L. Shen, M. Barnes, J. V. Milanovic, and R. Preece, "Control of VSCHVDC system integrated with AC network," in $10^{\text {th }}$ IET International Conference on AC and DC Power Transmission (ACDC 2012), Birmingham, UK, 2012.

[6] H. Liu, Z. Chen, "Contribution of VSC-HVDC to frequency regulation of power systems with offshore wind generation," IEEE Trans. Energy Conversion, vol. 30, no. 3, pp. 918-926, Sept. 2015.

[7] L. Zeni, B. Hesselbaek, P. E. Sorensen, A. D. Hansen, and P. C. Kjaer, "Control of VSC-HVDC in offshore AC islands with wind power plants: comparison of two alternatives," in IEEE PowerTech Conference Eindhoven. Eindhoven, Netherlands, July 2015.

[8] K. De Brabandere, B. Bolsens, J. Van den Keybus, A. Woyte, J. Driesen, and R. Belmans, "A voltage and frequency droop method for parallel inverters," IEEE Trans. Power Electronics, vol. 22, no. 4, pp. 1107-1115, Jul. 2007.

[9] P. Kundur, N. J. Balu, and M. G. Lauby, Power System Stability and Control, New York, USA: McGraw-Hill, 1994.

[10] M. Mohammadi, M. Avendano-Mora, M. Barnes, J. Y. Chen, "A study on fault ride-through of VSC connected offshore wind farms," in IEEE Power and Energy Society General Meeting, British Columbia, Canada, 21-25 July, 2013.

[11] L. Shi, S. Dai, Y. Ni, L. Yao, and M. Bazargan, "Transient stability of power systems with high penetration of DFIG based wind farms," in IEEE Power and Energy Society General Meeting, Calgary, Alberta, Canada, 26-30 July, 2009. 